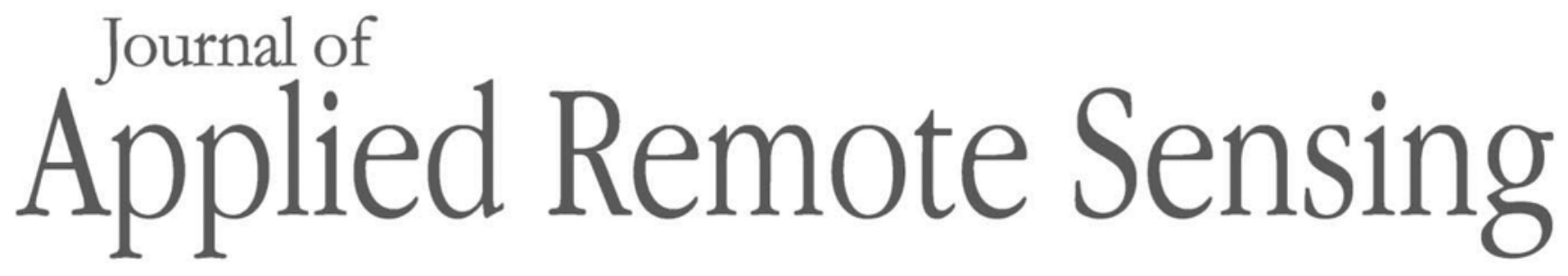

RemoteSensing.SPIEDigitalLibrary.org

\title{
Large-scale radiation and energy balances with Landsat 8 images and agrometeorological data in the Brazilian semiarid region
}

\author{
Antônio Heriberto de Castro Teixeira \\ Janice Freitas Leivas \\ Fernando Braz Tangerino Hernandez \\ Renato Alberto Momesso Franco
}

Antônio Heriberto de Castro Teixeira, Janice Freitas Leivas, Fernando Braz Tangerino Hernandez, Renato Alberto Momesso Franco, "Large-scale radiation and energy balances with Landsat 8 images and agrometeorological data in the Brazilian semiarid region," J. Appl. Remote Sens. 11(1), 016030 (2017), doi: 10.1117/1.JRS.11.016030. 


\title{
Large-scale radiation and energy balances with Landsat 8 images and agrometeorological data in the Brazilian semiarid region
}

\author{
Antônio Heriberto de Castro Teixeira, ${ }^{a}, *$ Janice Freitas Leivas, ${ }^{a}$ \\ Fernando Braz Tangerino Hernandez, ${ }^{b}$ and \\ Renato Alberto Momesso Franco ${ }^{b}$ \\ ${ }^{a}$ Embrapa Satellite Monitoring, Campinas, São Paulo, Brazil

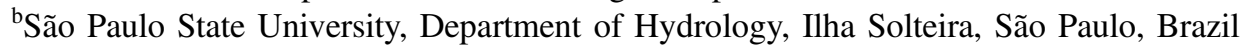

\begin{abstract}
Aiming to subsidize the rational water resources management, four Landsat 8 (L8) images along different conditions of the year 2014 were used for modeling the radiation and energy balances in the mixed agroecosystems inside a Brazilian reference semiarid area. The SAFER algorithm was applied to calculate the latent heat flux $(\lambda E)$; net radiation $\left(R_{n}\right)$ was acquired by the Slob equation; ground heat flux $(G)$ was considered a fraction of $R_{n}$; and the sensible heat flux $(H)$ was retrieved by residue in the energy balance equation. For classifying the vegetation, the surface resistance algorithm (SUREAL) was used to estimate the surface resistance to the water fluxes $\left(r_{s}\right)$ with threshold values for $r_{s}$. Clearly, one could see higher $\lambda E$ values from irrigated crops (ICs) than those for natural vegetation (NV) with some situations of heat horizontal advection. The respective $\lambda E, H$, and $G$ average ratios to $R_{n}$ for the ICs ecosystem were $64 \%$ to $79 \%, 18 \%$ to $28 \%$, and $3 \%$, respectively. For the NV ecosystem, the corresponding fractions were $4 \%$ to $37 \%, 60 \%$ to $94 \%$, and $4 \%$, respectively. The algorithms proved to have strong sensibility to quantifying the large-scale energy and mass exchanges by applying L8 images in mixed agroecosystems of semiarid environments. (C) 2017 Society of Photo-Optical Instrumentation Engineers (SPIE) [DOI: 10.1117/1.JRS.11.016030]
\end{abstract}

Keywords: net radiation; latent heat flux; sensible heat flux; soil heat flux; energy partition.

Paper 16519P received Jul. 7, 2016; accepted for publication Jan. 4, 2017; published online Feb. 22, 2017.

\section{Introduction}

Energy exchanges in semiarid regions have gained notoriety due to their agroecosystem dynamics and impacts on regional and local climates. The Petrolina County, Pernambuco state, in the Brazilian semiarid, is an example. Nowadays, it is highlighted as an important agricultural growing region because of the irrigation technologies applied to fruit crops at the vicinities of the São Francisco River. Under these rapid land-use changing conditions, the use of remote sensing by satellite images is strongly relevant for large-scale quantification of the energy and mass exchanges between the surface and the lower atmosphere and is the method used in distinct environments around the world. ${ }^{1-4}$

After taking into account all the radiation balance components, the net radiation $\left(R_{n}\right)$ is the difference between incoming and outgoing radiation fluxes of both short and long wavelengths. $R_{n}$ is partitioned into latent $(\lambda E)$, sensible $(H)$, and ground $(G)$ heat fluxes. ${ }^{5}$ Other energy terms, such as heat stored or released in/from the canopies or the energy used in metabolic activities, are in general not considered because they account only for a small fraction of the daily $R_{n}$ and may be neglected in environmental studies. ${ }^{6}$

The use of remote sensing by satellite images is a suitable way for determining and mapping the spatial and temporal structure of the radiation and energy balance components. Several

*Address all correspondence to: Antônio Heriberto de Castro Teixeira, E-mail: heriberto.teixeira@embrapa.br

$1931-3195 / 2017 / \$ 25.00$ (C) 2017 SPIE 
algorithms have been developed for this task, with some advantages and shortcomings, such as, the surface energy balance algorithm for land (SEBAL), ${ }^{7}$ the surface energy balance index (S-SEBI), ${ }^{8}$ and the surface energy balance system (SEBS). ${ }^{9}$

Although SEBAL had been calibrated and validated with field radiation and energy balance measurements, and presented a good performance in the Brazilian semiarid region, ${ }^{10,11}$ the major difficult in its applicability is the need for an anchor dry pixel for neglecting $\lambda E$. During the rainy season in this region, the mixed agroecosystems composed of irrigated crops (ICs) and natural vegetation (NV) are homogenously wet, all presenting high water fluxes, with $\lambda E$ values from the natural "Caatinga" species being even larger than those from irrigation plots in some occasions. ${ }^{6}$

Another problem in relation to the applicability of some remote sensing radiation and energy balance algorithms, when aiming at the end users, is the need for background knowledge in radiation physics. The use of the Penman-Monteith (PM) equation has been suggested for applying remotely sensed vegetation indices, such as the normalized difference vegetation index (NDVI) and the enhanced vegetation index, together with weather data. ${ }^{12,13}$ The PM equation is also highlighted by both the use of the crop coefficient $\left(K_{c}\right)$ approach $^{5,14}$ and the model named mapping evapotranspiration with high-resolution and internalized calibration (METRIC). ${ }^{15}$

Considering the simplicity of the PM equation for large-scale applications, two algorithms based on this equation were developed and validated under the Brazilian semiarid conditions. ${ }^{1}$ They are called simple algorithm for evapotranspiration retrieving (SAFER), which is based on the modeled ratio of the actual (ET) to the reference $\left(\mathrm{ET}_{0}\right)$ evapotranspiration to acquire $\lambda E$, and surface resistance algorithm (SUREAL) for estimating the surface resistance to the water fluxes $\left(r_{s}\right)$. This last model has been successfully applied for classifying ICs and NV in the mixed Brazilian semiarid agroecosystems. ${ }^{6}$ To elaborate and validate these algorithms, field data from four flux stations were used together with satellite images involving ICs and $\mathrm{NV}$ agroecosystems under strong contrasting thermohydrological and surface cover conditions over several years. ${ }^{1,16}$

Hernandez et al. ${ }^{17}$ compared the SAFER and SEBAL algorithms with the $K_{c}$ approach ${ }^{5}$ in the Northwestern side of the São Paulo state, Brazil. These applications were done on corn, beans, and sugarcane crops that were irrigated by center pivots. According to the authors, SAFER presented better performance than SEBAL under the conditions of low soil cover by the canopies.

The Landsat 8 (L8) satellite was launched on February 11, 2013, and normal operations started on May 30, 2013. It has a 16-day ground track repeat cycle with an equatorial crossing time at 10:00 a.m. The Operational Land Imager on L8 is a nine-band push broom scanner with a swath width of $185 \mathrm{~km} .{ }^{18}$ Some radiation and energy balance studies using remote sensing data have been carried out in the Brazilian semiarid region but with limitations of free-cloud cover images with just one Landsat 5/7 image in a year. However, new research is needed to test the suitability of the L8 satellite for these studies, especially with the availability of images covering different seasons as in the case of the current paper. These new studies are important for operationally monitoring the energy exchanges among the different agroecosystems to assist large-scale water management. ${ }^{19}$

The objective of the current research is to apply the SAFER and SUREAL algorithms with L8 images together with a net of agrometeorological stations, covering different seasons of the year 2014, aiming to quantify the large-scale radiation and energy balance components. The results can subsidize criteria for policy decisions aimed at rational water resources management under conditions of rapid land-use and climate changes together with water competitions among different sectors. The success of the modeling with the L8 satellite images may give more confidence for testing and validating the algorithms in other environments around the world, which probably will only need calibrations of the original equations.

\section{Material and Methods}

\subsection{Study Area and Dataset}

Figure 1 shows the location of the reference semiarid area (dashed red square on the right side) inside the Petrolina County, Pernambuco state, Northeast of Brazil, together with the net of seven 


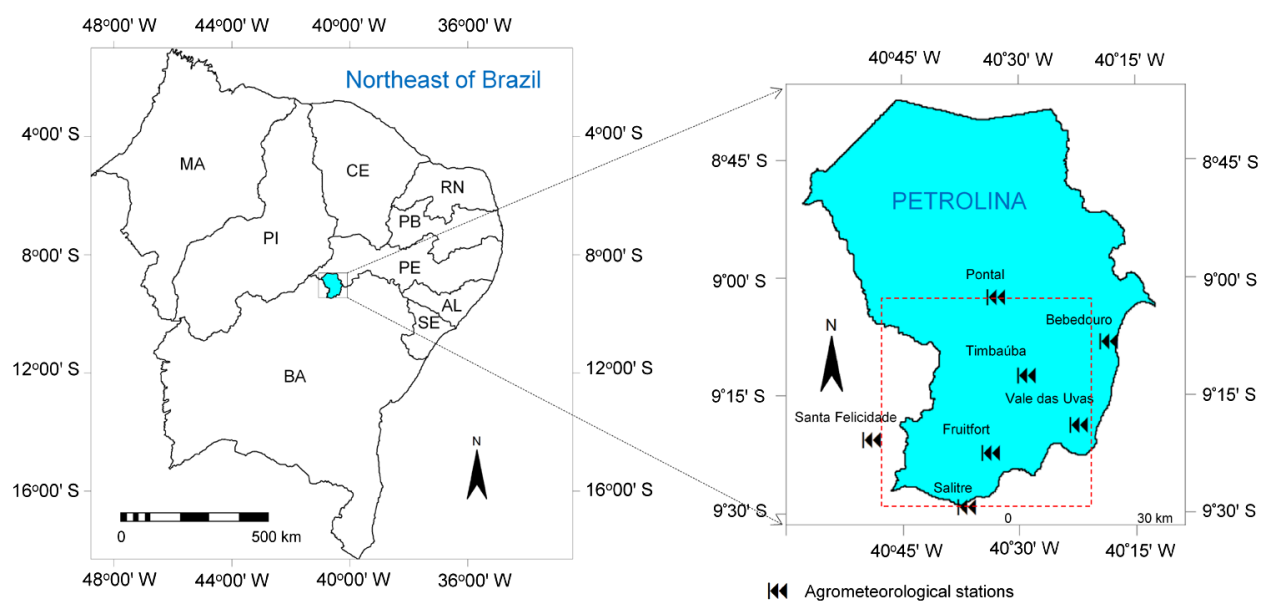

Fig. 1 Location of the reference semiarid area (dashed red square on the right side) inside the Petrolina County, Pernambuco state, Northeast Brazil and the agrometeorological stations used for the weather data interpolation processes in a GIS environment.

agrometeorological stations (black arrows) used for the weather data interpolation processes in a geographic information system (GIS) environment.

According to Teixeira, ${ }^{20}$ in the reference semiarid area shown in Fig. 1, excluding a very few high-altitude places, all the flat areas present long-term annual air temperature $\left(T_{a}\right)$ higher than $24^{\circ} \mathrm{C}$. The average monthly maximum value is $33^{\circ} \mathrm{C}$ and the minimum is $19^{\circ} \mathrm{C}$. The warmest months are October and November when the sun is around the zenith position with low cloud cover, while the coldest months are June and July, at the winter solstice in the south hemisphere. The thermal homogeneity strongly contrasts with the spatial and temporal heterogeneity of the rainfall regime. Most rains fall during the first four months of the year, accounting for $68 \%$ of the annual total, which presents a long-term (50 years) value of $570 \mathrm{~mm} \mathrm{yr}^{-1}$ registered at the "Bebedouro" station (see Fig. 1). The sandy soil is classified as Latossoil red-yellow with low retention capacity with a groundwater depth of around $2.5 \mathrm{~m}$.

The ICs agroecosystem is composed mainly of fruit crops, with the main ones being grapes, mangos, guava, and bananas, surrounded by the NV ecosystem ("Caatinga"). The "Caatinga" species are defined as bushes that possess small leaves or thorns. During the dry seasons they become senescent; however, as soon as the rains start, the plants rapidly turn green. Some of them lose their leaves in the dry periods, and others store water, being adapted to tolerate water stress and thrive under environmental constraints, which increases their rainfall water productivity.

Data from seven agrometeorological stations (see Fig. 1) were used together with four L8 images acquired under different thermohydrological conditions in the year 2014 [day of the year (DOY): 25-January, 25; 153-June, 2; 217-August, 5; and 265-September, 22]. Grids of global solar radiation $\left(R_{G}\right), T_{a}$, and $\mathrm{ET}_{0}$ from the stations were used together with the remotely sensed retrieved parameters during the modeling steps for the large-scale radiation and energy balance components estimations. ${ }^{6}$ The grids of weather data with the same pixel sizes of the L8 images were constructed using the "moving average" interpolation method in a GIS environment.

\subsection{Large-Scale Radiation and Energy Balances Modeling}

Figure 2 presents the flowchart for the large-scale radiation and energy balance modeling, using L8 images together with agrometeorological data through the SAFER algorithm. The bands 1 to 7 (spatial resolution of $30 \mathrm{~m}$ ) were used to calculate the surface albedo $\left(\alpha_{0}\right)$, bands 4 and 5 were used to retrieve NDVI, and the surface temperature $\left(T_{0}\right)$ was estimated using the bands 10 and 11 (spatial resolution of $100 \mathrm{~m}$ ).

All the regression coefficients of the equations for acquiring the parameters in Fig. 2 were determined in the reference semiarid area shown in Fig. 1 with simultaneous Landsat satellite 


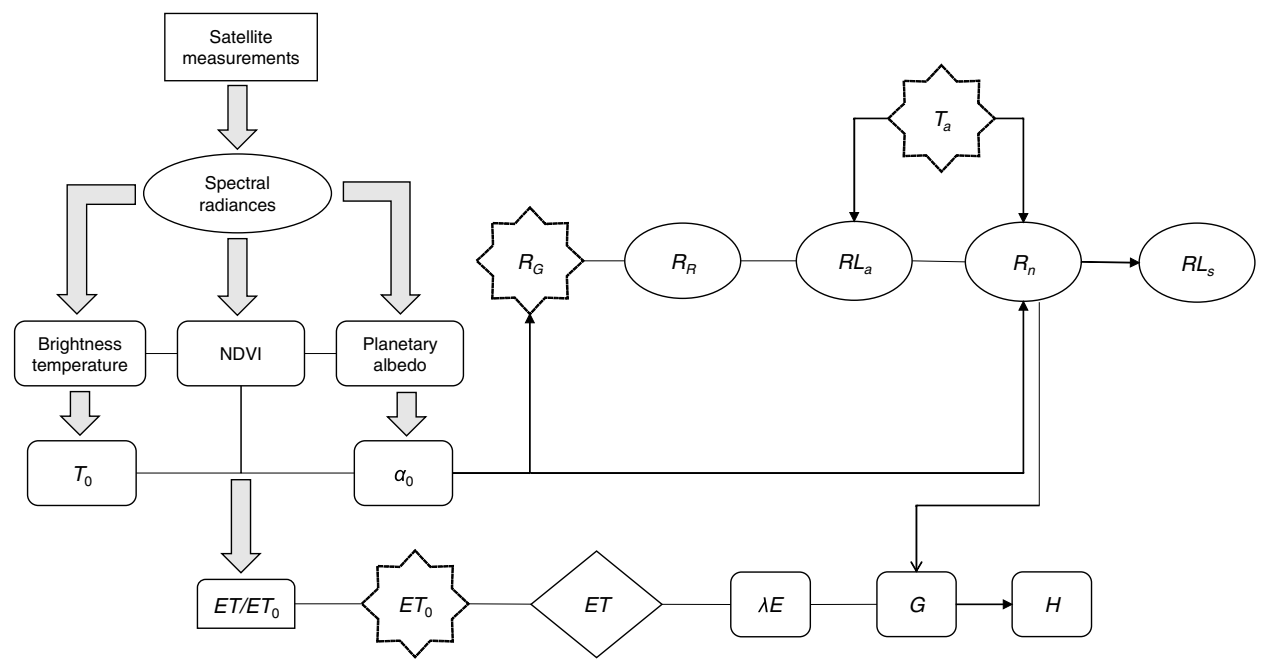

Fig. 2 Flowchart for the large-scale radiation and energy balances by applying the SAFER using L8 images together with agrometeorological data.

and field measurements, involving strongly contrasting agroecosystems and under different thermohydrological conditions throughout several years. $1,6,10,16$

Following Fig. 2, the spectral radiances $\left(L_{b}\right)$ were computed from digital numbers (DN)

$$
L_{b}=\text { Gain } x \mathrm{DN}+\text { Offset, }
$$

where Gain and Offset refer to the values given in the Landsat metadata file. ${ }^{18}$

The planetary albedo for each Landsat satellite band $\left(\alpha p_{b}\right)$ was calculated as

$$
\alpha p_{b}=\frac{L_{b} \pi d^{2}}{R a_{b} \cos \varphi},
$$

where $L_{b}$ is the spectral radiance for the wavelengths of band $b\left(\mathrm{~W} \mathrm{~m}^{-2} \mathrm{sr}^{-1} \mu \mathrm{m}^{-1}\right), d$ is the relative earth-sun distance, $R a_{b}$ is the mean solar irradiance at the top of the atmosphere (or atmospheric irradiance) for each band $\left(\mathrm{W} \mathrm{m}^{-2} \mu \mathrm{m}^{-1}\right)$, and $\varphi$ is the solar zenith angle. ${ }^{6}$

$R a_{b}$ for each of the L8 bands 1 to 7 was calculated according to Planck's law, integrating the radiation over the wavelength intervals and considering their fractions over the solar spectrum, assuming the sun as a blackbody. Then, the broadband planetary albedo $\left(\alpha_{p}\right)$ was obtained as the total sum of the different narrow-band $\alpha p_{b}$ values according to their weights $\left(w_{b}\right)$

$$
\alpha p=\sum w_{b} \alpha p_{b}
$$

where the $w_{b}$ values were computed as the ratio of the amount of the incoming shortwave (sw) radiation from the sun at the top of the atmosphere in a particular band and the sum for all the bands.

Table 1 shows the wavelengths, $R a_{b}$ and $w_{b}$ for each of the bands used (B1-B7) in the $\alpha_{p}$ calculations from the spectral L8 measurements.

The spectral radiances from the L8 bands $10\left(L_{10}\right)$ and $11\left(L_{11}\right)$ were converted into radiometric temperatures applicable at the top of the atmosphere $\left(T_{b}\right)$ by inversion of the Planck's law in the 10.6- to $11.19-\mu \mathrm{m}$ (band 10) and 11.5- to 12.51- $\mu \mathrm{m}$ (band 11) bandwidth

$$
T_{b}=\frac{K_{2}}{\ln \left(\frac{K_{1}}{L_{b}+1}\right)},
$$

where $K_{1}$ (774.89 and 480.89) and $K_{2}$ (1321.08 and 1201.14) for bands 10 and 11, respectively, are conversion coefficients for the L8 satellite. 
Table 1 Radiometric parameters for the planetary albedo $\left(\alpha_{p}\right)$ calculations from the L8 images: wavelengths of the bands- $\lambda_{b}$; mean solar irradiance at the top of the atmosphere for each band- $R a_{b}$; and the weights for each band $-w_{b}$.

\begin{tabular}{lccccccc}
\hline \hline L8 parameter & $\mathrm{B} 1$ & $\mathrm{~B} 2$ & $\mathrm{~B} 3$ & $\mathrm{~B} 4$ & $\mathrm{~B} 5$ & $\mathrm{~B} 6$ & $\mathrm{~B} 7$ \\
\hline$\lambda_{b}(\mu \mathrm{m})$ & $\begin{array}{c}0.43 \text { to } \\
0.45\end{array}$ & $\begin{array}{c}0.45 \text { to } \\
0.51\end{array}$ & $\begin{array}{c}0.53 \text { to } \\
0.59\end{array}$ & $\begin{array}{c}0.64 \text { to } \\
0.67\end{array}$ & $\begin{array}{c}0.85 \text { to } \\
0.88\end{array}$ & $\begin{array}{c}1.57 \text { to } \\
1.65\end{array}$ & $\begin{array}{c}2.11 \text { to } \\
2.29\end{array}$ \\
$R a_{b}\left(\mathrm{~W} \mathrm{~m}^{-2} \mu \mathrm{m}^{-1}\right)$ & 1718.8 & 1810.4 & 1741.7 & 1558.3 & 962.5 & 206.3 & 68.8 \\
$w_{b}$ & 0.10 & 0.31 & 0.30 & 0.13 & 0.08 & 0.05 & 0.04 \\
\hline \hline
\end{tabular}

The average $T_{b}$ value from the two bands was considered the brightness temperature ( $T_{\text {bright }}$ ); however, conditional functions were used when one of the bands 10 or 11 presented pixel value problems to retrieve only one band Planck's result for $T_{\text {bright }}$.

Both $\alpha_{p}$ and $T_{\text {bright }}$ were corrected atmospherically for acquiring the surface instantaneous values of albedo $\left(\alpha_{0}\right)$ and temperature $\left(T_{0}\right)$ by regression equations determined from previous simultaneous Landsat and field measurements. Another regression between the instantaneous and daily values was also applied to upscale the satellite overpass to the 24-hour $\alpha_{0}$ and $T_{0}$ values. ${ }^{1,6,10,16}$

NDVI is a land cover and water-related indicator obtained from satellite images as

$$
\mathrm{NDVI}=\frac{\alpha p_{(\mathrm{nir})}-\alpha p_{(\mathrm{red})}}{\alpha p_{(\mathrm{nir})}+\alpha p_{(\mathrm{red})}}
$$

where $\alpha p_{\text {nir }}$ and $\alpha p_{\text {red }}$ represent the planetary albedo over the wavelength ranges in the nearinfrared (subscript nir) and red (subscript red) regions of the solar spectrum, which for the L8 satellite are the bands 5 (B5) and 4 (B4), respectively (see Table 1).

Daily $R_{n}$ was calculated using the Slob equation ${ }^{7,16,20,21}$

$$
R_{n}=\left(1-\alpha_{0}\right) R_{G}-a_{L} \tau_{\mathrm{sw}},
$$

where $\tau_{\mathrm{sw}}$ is the sw atmospheric transmissivity calculated as the ratio of $R_{G}$ to the incident solar radiation at the top of the atmosphere $\left(R_{a}\right)$ and the regression coefficient $a_{L}$ was spatially distributed through its relationship with $T_{a}{ }^{20}$

$$
a_{L}=a T_{a}-b,
$$

A constant value for $a_{L}=110$ was previously used without considering the thermal spatial differences. $^{7}$

The atmospheric longwave radiation $\left(R L_{a}\right)$ was calculated by applying the StefanBoltzmann law

$$
R L_{a}=\sigma \varepsilon_{A} T_{a}^{4},
$$

where $\varepsilon_{A}$ was estimated as follows: ${ }^{1,6,10,16}$

$$
\varepsilon_{A}=a_{A}\left(-\ln \tau_{\mathrm{sw}}\right)^{b_{A}},
$$

where the regression coefficients $a_{A}$ and $b_{A}$ of 0.94 and 0.11 are between those for Idaho ${ }^{22}$ $\left(a_{A}=0.85\right.$ and $\left.b_{A}=0.09\right)$ and for $\operatorname{Egypt}^{7}\left(a_{A}=1.08\right.$ and $\left.b_{A}=0.26\right)$.

Estimating the reflected solar radiation $\left(R_{R}\right)$ as the product of $R_{G}$ by $\alpha_{0}$, the daily longwave surface radiation $\left(R L_{s}\right)$ was retrieved as residue in the radiation balance equation

$$
\begin{gathered}
R_{R}=\alpha_{0} R_{G}, \\
R L_{s}=R_{G}-R_{R}+R L_{a}-R_{n} .
\end{gathered}
$$


Applying the SAFER algorithm, the ratio of the actual (ET) to the reference $\left(\mathrm{ET}_{0}\right)$ evapotranspiration, $\mathrm{ET}_{r}$, was modeled at the satellite overpass time

$$
\mathrm{ET}_{r}=\exp \left[a_{s f}+b_{s f}\left(\frac{T_{0}}{\alpha_{0} \mathrm{NDVI}}\right)\right]
$$

where $a_{s f}$ and $b_{s f}$ are the regression coefficients for the reference semiarid area.,6

The $\mathrm{ET}_{0}$ daily grids were obtained by applying the $\mathrm{PM}$ method $^{5}$ interpolating the weather data from the agrometeorological stations (black arrows on Fig. 1), and then multiplied by the images resulting from Eq. (12), giving the large-scale daily ET pixel values, which were transformed into energy units to retrieve $\lambda E$

$$
\mathrm{ET}=\mathrm{ET}_{r} \mathrm{ET}_{0} .
$$

Equation (12) does not work for water bodies, i.e., when NDVI $<0$. Thus, the concept of equilibrium evapotranspiration $\left(\mathrm{ET}_{\mathrm{eq}}\right)^{23}$ is adopted under these conditions in the SAFER algorithm, and $\lambda E_{\text {eq }}$ is retrieved through conditional functions applied to the NDVI values as

$$
\lambda E_{\mathrm{eq}}=\frac{s\left(R_{n}-G\right)}{s+\gamma},
$$

where $s$ is the slope of the curve relating saturation water vapor pressure to $T_{a}$ and $\gamma$ is the psychometric constant. Under these conditions, as the surface moisture availability is not constrained, water vapor transfer is only limited by the available energy.

For the daily $G$ values, the following equation was used: ${ }^{1,6}$

$$
\frac{G}{R_{n}}=a_{G} \exp \left(b_{G} \alpha_{0}\right)
$$

where $a_{G}$ and $b_{G}$ are regression coefficients for the reference semiarid region.

The sensible heat flux $(H)$ was estimated as residue in the energy balance equation ${ }^{19}$

$$
H=R_{n}-\lambda E-G .
$$

For classification of the vegetated surface into ICs and NV ecosystems, the SUREAL model was applied ${ }^{1,24}$

$$
r_{s}=\exp \left[a_{r}\left(\frac{T_{0}}{\alpha_{0}}\right)(1-\mathrm{NDVI})+b_{r}\right],
$$

where $a_{r}$ and $b_{r}$ are regression coefficients for the reference semiarid region.

Pixels with $r_{s}$ values below $800 \mathrm{~s} \mathrm{~m}^{-1}$ and NDVI above or equal to 0.40 were considered the ICs agroecosystem. If $r_{s}$ was between 1000 and $10,000 \mathrm{~s} \mathrm{~m}^{-1}$, the pixels should be the NV ecosystem. The high end of this last range was used to exclude human-built structures.

\section{Results and Discussion}

\subsection{Weather Drivers}

The weather-driving forces for the radiation and energy balances are $R_{G}$, precipitation $(P)$, and the atmospheric demand represented by $\mathrm{ET}_{0}$. These parameters were analyzed on a daily scale during the transition periods comprising the start of the rainy season in 2013 to the end of the dry season in 2014, involving the previous, current, and post-thermohydrological conditions of the satellite image acquisition dates (January to September of 2014).

Figure 3 shows the daily trends of $R_{G}, P$, and $\mathrm{ET}_{0}$ in terms of DOY with weather data from the "Timbaúba" agrometeorological station, located in the center of the reference semiarid area inside the Petrolina County, Brazilian Northeast region (see Fig. 1). 


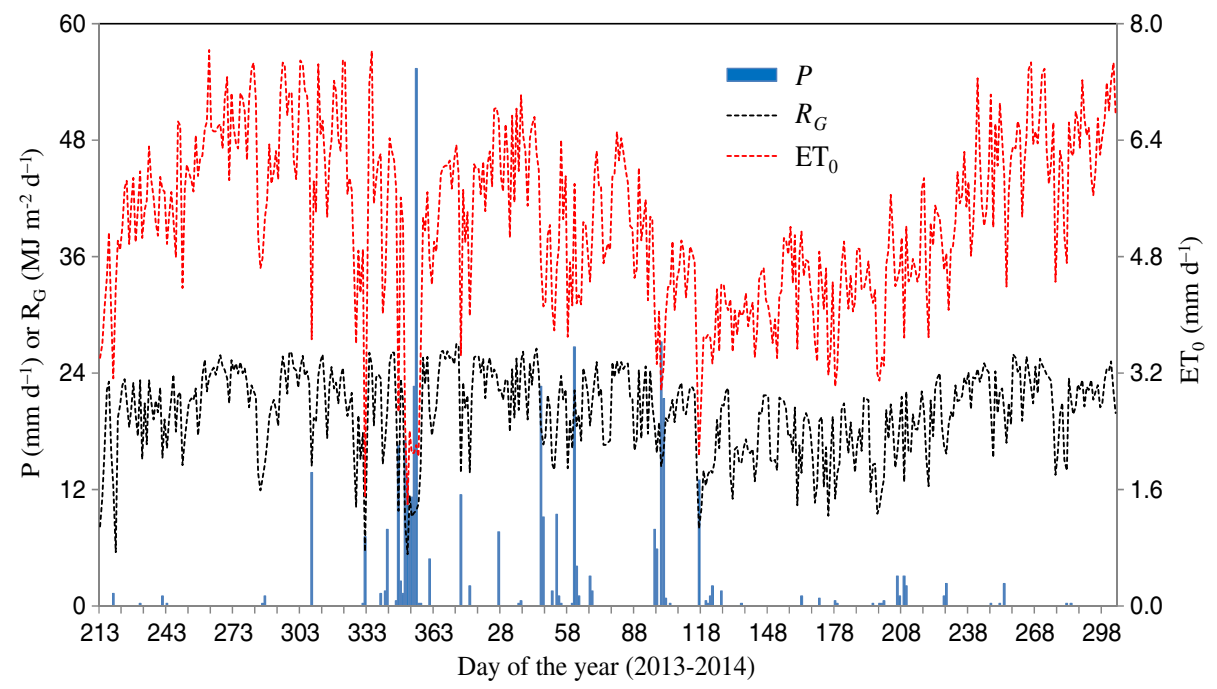

Fig. 3 Trends of the daily values of precipitation $(P)$, incident global solar radiation $\left(R_{G}\right)$, and reference evapotranspiration $\left(\mathrm{ET}_{0}\right)$, involving the DOY from the start of the rainy period in November/2013 to the end of the dry period in October/2014, in the reference semiarid area of Petrolina County, Brazilian Northeast region.

Among the analyzed weather parameters, $P$ was the most variable in the study period. The rain concentrations were from DOY/year 303/2013 to 120/2014 (November to April), mainly at the end of 2013. The climatically driest periods, with $P$ below $5 \mathrm{~mm} \mathrm{~d}^{-1}$, were from DOY 210 to 300 of 2014 (August to October).

Analyzing the daily atmospheric demands, the largest $\mathrm{ET}_{0}$ values happened between DOY 242 and 304 of 2014 (September to October), when they reached around $7.0 \mathrm{~mm} \mathrm{~d}^{-1}$. In these situations, the sun was at the zenith position under low cloud cover conditions. The $R_{G}$ daily values were higher than $25 \mathrm{MJ} \mathrm{m}^{-2} \mathrm{~d}^{-1}$ at the end of both years and below $10 \mathrm{MJ} \mathrm{m}^{-2} \mathrm{~d}^{-1}$ in the middle of 2014 , with these levels significantly related to the sun astronomical positions.

Under conditions of high $P, \mathrm{ET}_{0}$, and $R_{G}$ in the second half of the year, both $\mathrm{NV}$ and ICs agroecosystems are in favor of large water fluxes; however, with absence of rains, only the ICs will present high rates, promoting strong hydrological contrast when compared with the natural "Caatinga" species.

\subsection{Remote Sensing Modeling Input Parameters}

The radiation and energy balances among the different agroecosystems and thermohydrological conditions will depend on $\alpha_{0}$, NDVI, and $T_{0}$. The first parameter determines the sw radiation that comes back from the surface to the lower atmosphere. NDVI is a key remote sensing indicator related to the land cover and soil moisture, and the emitted longwave radiation is directly proportional to $T_{0}$.

The spatial distributions for the daily values of the remote sensing input parameters, in the reference semiarid area of the Petrolina County, Brazilian Northeast, are shown in Fig. 4.

A darker land surface, i.e., with a low $\alpha_{0}$, absorbs more solar radiation and has a larger available energy than a brighter one, but this also depends on the soil moisture conditions. ${ }^{16,25,26}$ The highest $\alpha_{0}$ values in the mixed agroecosystems occurred in the image of DOY 265 (September 22), representing the driest period of the year in which the joint effects of low both soil moisture and cloud cover, together with the sun's astronomical position near the zenith position, produce large $R_{G}$ levels.

However, the $\alpha_{0}$ spatial variations were homogeneous along the different periods of the year with standard deviation (SD) of 0.02 in all images, with no strong distinctions among the ICs and $\mathrm{NV}$ agroecosystems. Clearly, one can see the largest $\alpha_{0}$ values in the southern part of the study area, where the Petrolina city is located, close to the São Francisco River. 


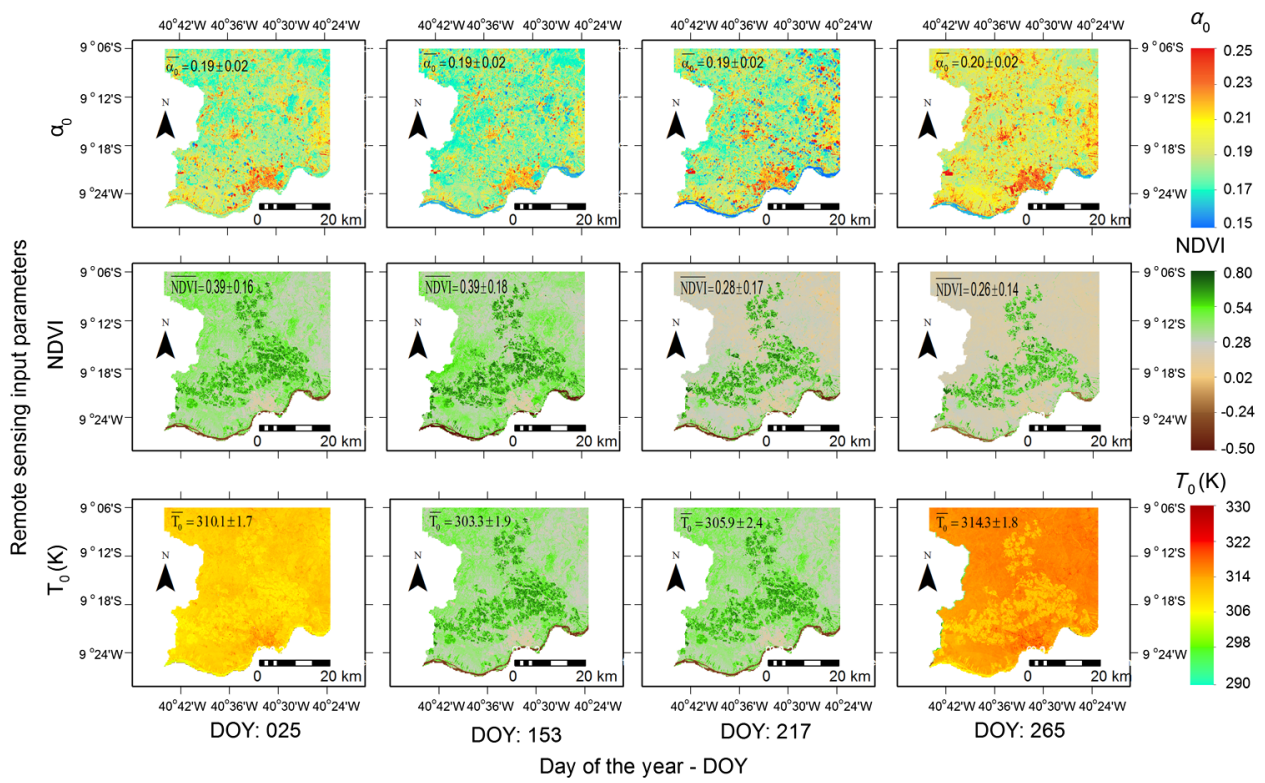

Fig. 4 Spatial distributions of the daily values for the remote sensing modeling input parameters in the reference semiarid area of Petrolina County, Pernambuco, Brazilian Northeast. Surface albedo $\left(\alpha_{0}\right)$, NDVI, and surface temperature $\left(T_{0}\right)$. Overbars mean average pixel values, shown together with the SD.

A similar $\alpha_{0}$ range, between 0.15 and 0.26 , was reported for tropical $\mathrm{NV},{ }^{27}$ but the values found in the current study are higher than those previously reported for humid tropical regions. ${ }^{28-30}$ The relation of $\alpha_{0}$ with environmental and moisture conditions is also in accordance with other more recent studies. ${ }^{6,19,25,26,31}$

The distinctions among the NDVI large-scale values in the year and among agroecosystems are much clear than in the case of $\alpha_{0}$, with the highest differences happening under the driest conditions of the year, at the end of September (DOY 265). On one hand, the largest pixel values are from January to June, represented by the images of DOY 25 and 153 because the NV species ("Caatinga") consume water from the first rains, increasing biomass production (BIO). On the other hand, ICs, besides the rainfall water consumption, are regularly irrigated daily.

As there is a relation between $\mathrm{BIO}$ and $\lambda E,{ }^{32}$ the water flux rates are higher in ICs than in NV ecosystems. Corn crops presented twice the BIO values when compared with natural alpine meadow in the Heithe River Basin, with irrigation considered the main reason for these strong differences. ${ }^{33}$ The lowest large-scale NDVI values were observed in September (DOY 265), when far from the rainy period, the soil in the root zone of the natural species was dry, promoting their senescence stages.

The $T_{0}$ parameter affects the energy available by acting in the long wave radiation balance, with its lower values under irrigation conditions than those from the drier areas in the vicinities of irrigated plots. However, even differentiating the agroecosystems better than $\alpha_{0}$, these distinctions are not as strong as those promoted by the NDVI pixel values. One reason for this is the lower spatial resolution of the thermal band $(100 \mathrm{~m})$ compared with the visible ones $(30 \mathrm{~m})$ of the $\mathrm{L} 8$ sensor.

In general, the periods with the highest $T_{0}$ values coincided with those of the largest $R_{G}$ levels (DOY 25 and 265, in January and September, respectively). The lowest $T_{0}$ occurred in the middle of the year, after the rainy season (DOY 153-June), which is due to the uniform soil moisture in the root zones of the mixed agroecosystems together with the winter solstice time in the south hemisphere.

The variability of $\alpha_{0}$, NDVI, and $T_{0}$ in the "Caatinga" natural ecosystem can primarily be attributed to variations in $R_{G}$ and surface moisture conditions due to consequences of the joint effects of sun position, cloud cover, and rainfall. However, for ICs, as the water is in general regularly applied, the magnitudes of these remote sensing parameters are also influenced by the different crop stages together with water and fertilization management. 
Table 2 Daily averages of the radiation balance components $\left(\mathrm{RB}_{\mathrm{comp}}\right)$ for the mixed agroecosystems, composed by ICs and NV, under different thermohydrological conditions, in the reference semiarid area inside the Petrolina County, Pernambuco, Northeast Brazil: incident global solar radiation $\left(R_{G}\right)$, reflected solar radiation $\left(R_{R}\right)$, atmospheric emitted longwave radiation $\left(R L_{a}\right)$, and surface emitted longwave radiation $\left(R L_{s}\right)$.

\begin{tabular}{|c|c|c|c|c|c|c|c|c|}
\hline \multirow{2}{*}{$\frac{\mathrm{DOY} / \mathrm{RB}_{\mathrm{comp}}}{\mathrm{DOY}}$} & \multicolumn{2}{|c|}{$R_{G}\left(\mathrm{MJ} \mathrm{m}^{-2} \mathrm{~d}^{-1}\right)$} & \multicolumn{2}{|c|}{$R_{R}\left(\mathrm{MJ} \mathrm{m}^{-2} \mathrm{~d}^{-1}\right)$} & \multicolumn{2}{|c|}{$R L_{a}\left(\mathrm{MJ} \mathrm{m}^{-2} \mathrm{~d}^{-1}\right)$} & \multicolumn{2}{|c|}{$R L_{s}\left(\mathrm{MJ} \mathrm{m}^{-2} \mathrm{~d}^{-1}\right)$} \\
\hline & ICs & NV & ICs & NV & ICs & NV & ICs & NV \\
\hline 25 & 24.13 & 24.23 & 4.59 & 4.61 & 34.70 & 34.67 & 42.87 & 42.88 \\
\hline 153 & 19.99 & 19.89 & 3.69 & 3.70 & 32.02 & 32.01 & 39.29 & 39.22 \\
\hline 217 & 19.31 & 19.20 & 3.63 & 3.65 & 32.96 & 32.98 & 39.69 & 39.65 \\
\hline 265 & 23.92 & 23.90 & 4.67 & 4.81 & 34.87 & 34.89 & 44.16 & 44.16 \\
\hline Mean & 21.84 & 21.81 & 4.15 & 4.19 & 33.64 & 33.64 & 41.50 & 41.48 \\
\hline
\end{tabular}

Note: DOY, day of the year.

\subsection{Large-Scale Radiation Balance}

Table 2 presents the mean daily pixel values of the radiation balance components $\left(\mathrm{RB}_{\text {comp }}\right)$ for the ICs and NV agroecosystems in the reference semiarid area, involving different thermohydrological conditions in the year 2014 inside the Petrolina County, Brazilian Northeast.

The incident global solar radiation $\left(R_{G}\right)$, considered the direct or indirect (diffuse) radiation from the sun, integrated over all wavelengths in the sw interval, presented seasonal variations in the year 2014, however, with similar values inside the ICs and NV areas. The highest $R_{G}$ levels occurred in January (DOY 25), during the rainy season, while the smallest ones were in August (DOY 217), during the naturally dry period.

The values of the reflected solar radiation $\left(R_{R}\right)$ followed those for $R_{G}$, but $R_{R}$ was also affected by the soil moisture and soil cover conditions, however, without strong differences among the agroecosystem types. The $R_{G}$ and $R_{R}$ accounting gives the sw radiation balance, determining the fraction of solar radiation that is absorbed by the surfaces and converted into heat energy. By several processes, including emission, the surfaces lose this energy as longwave radiation.

The atmosphere absorbs the emitted longwave radiation from the surfaces $\left(R L_{s}\right)$ or loses it into space. In general, $R L_{s}$ presented seasonal variations, according to $R_{G}$ levels, but with less dependence on the agroecosystem types when compared with $R_{R}$. Part of $R L_{s}$ finds its way back to the surfaces as emitted longwave radiation from the atmosphere $\left(R L_{a}\right)$.

$R L_{a}$ is dependent on $T_{a}$ and on the concentration of carbon dioxide, water vapor, and ozone. $R L_{s}$ values always stayed above the $R L_{a}$ ones, by $20 \%$ in January (DOY 25) and 27\% in August (DOY 217), independent of the surface type. As $R L_{s}$ was usually greater than $R L_{a}$, the net longwave radiation represented an energy loss from the Brazilian semiarid agroecosystems to the lower atmosphere.

Taking into account all components from Table 2 , the $R_{n}$ represents the difference between incoming and outgoing radiation of both short and long wavelengths. The fraction of $R_{G}$ transformed into $R_{n}$ ranged from $41 \%$ (DOY 217, August) to 47\% (DOY 25, January), averaging $45 \%$, independent of the agroecosystem type. This is in agreement with field measurements in ICs and NV done inside the semiarid region of Brazil ${ }^{16}$ and with studies involving other agroecosystems, ${ }^{34,35}$ giving additional confidence to SAFER for the large-scale radiation and energy balance acquirements by the coupled use of L8 images and agrometeorological stations.

Using $R_{G}$ and $T_{a}$ interpolated data together with $\alpha_{0}$ on a daily scale, the Slob equation [Eq. (6)] was applied to retrieve the 24-hour large-scale $R_{n}$ values ${ }^{7,16,20,21}$ (Fig. 5).

In general, there were no clear $R_{n}$ distinctions among irrigated and $\mathrm{NV}$ areas and no large spatial differences, with the SDs ranging from 0.6 to $0.9 \mathrm{MJ} \mathrm{m}^{-2} \mathrm{~d}^{-1}$. Its strongest dependence 


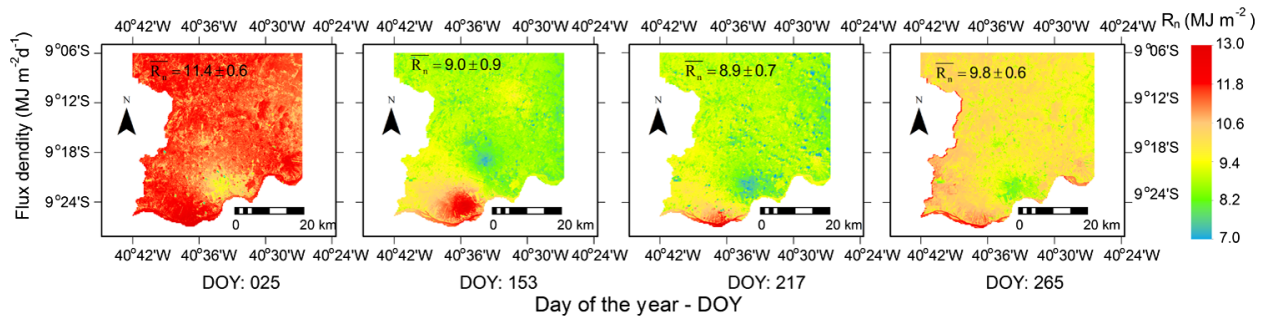

Fig. 5 Spatial distribution of the daily $R_{n}$ values in the reference semiarid area inside Petrolina County, Pernambuco, Brazilian Northeast. Overbars mean average pixel values, shown together with the SDs.

was on $R_{G}$ as the largest mean $R_{n}$ pixel values for January (DOY 25) and September (DOY 265) corresponded to the highest $R_{G}$ ones (see Fig. 5 and Table 2).

It is clear from Fig. 5 that one cannot classify the $R_{n}$ values according to the agroecosystem types in the Brazilian semiarid region. Then, spatial differences among ICs and NV should be detected when considering the energy partitions into $\lambda E, H$, and $G$, according to the different thermohydrological conditions in the year. These analyses are carried out in Sec. 3.4.

\subsection{Large-Scale Energy Balance}

Acquiring ET through the SAFER algorithm and transforming it into energy units, ${ }^{6,19} \lambda E$ was estimated. Considering $G$ to be a fraction of $R_{n}$ and $H$ retrieved as residue in the energy balance equation, all components of this balance could be spatially determined. ${ }^{19}$

Figure 6 presents the spatial distribution of the daily values for $\lambda E, H$, and $G$ in the reference semiarid area inside the Petrolina County, Pernambuco state, Northeast of Brazil, for each DOY, involving different thermohydrological conditions in the year 2014.

Clearly, one can distinguish irrigated areas and water bodies from the NV by the highest crop $\lambda E$ pixel values, according to the period of the year, primarily when looking for the image of DOY 265 (September), which represents the climatically driest condition. In some pixels, $\lambda E$
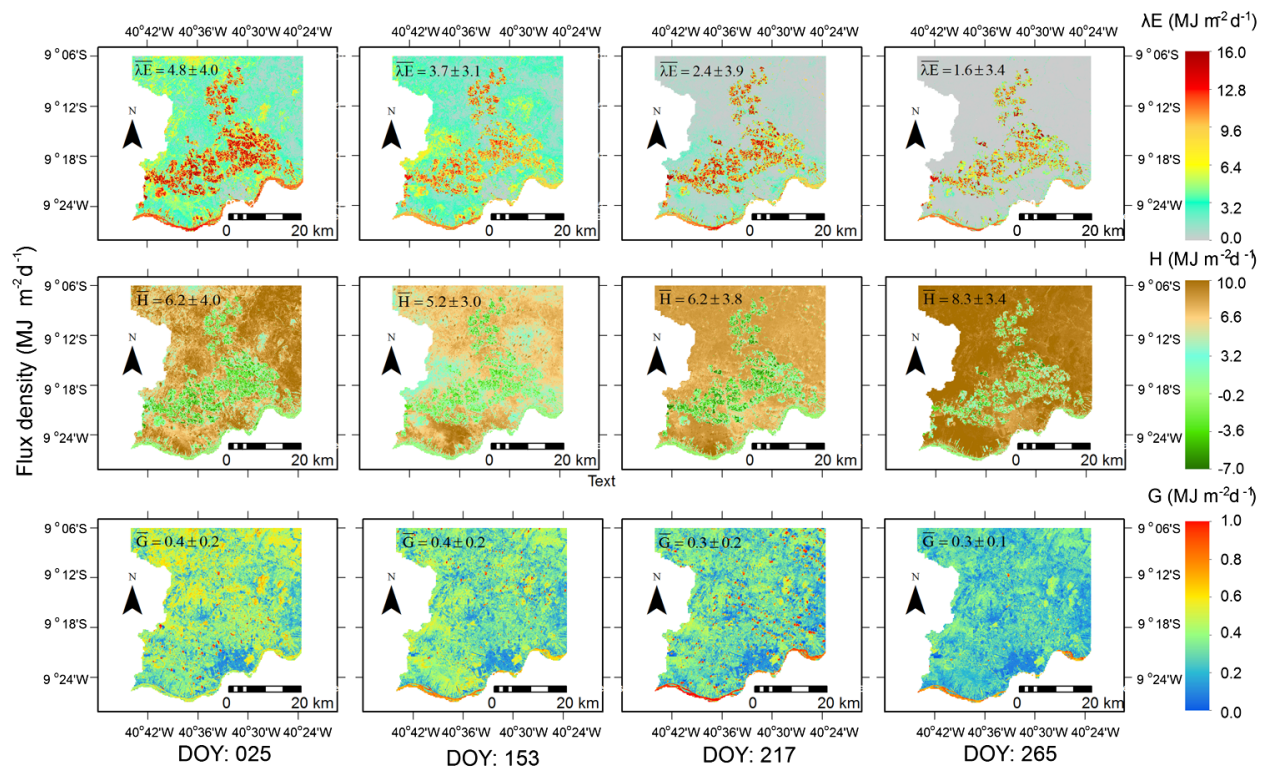

$9^{\circ} 12^{\prime} \mathrm{s}-6.6$

$0^{\circ} 18 \cdot 5$

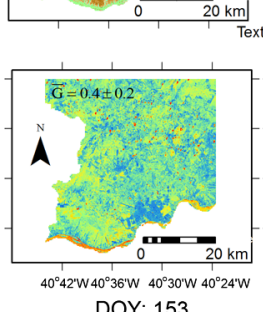

DOY: 153
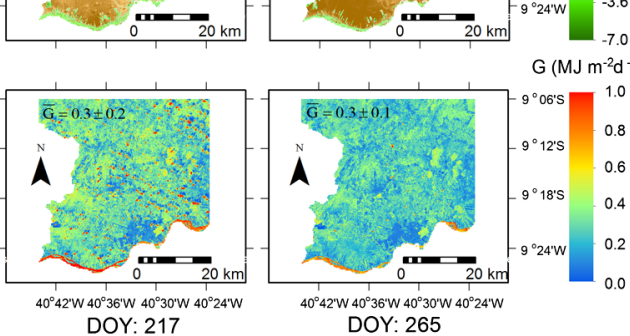

$G\left(M J m^{-2} d-1\right)$

Day of the year - DOY

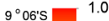

0.8

$9^{\circ} 12^{\prime} \mathrm{S}$

$9^{\circ} 18^{\prime} \mathrm{s} \quad 0.4$

$9^{\circ} 24 \mathrm{~W}$

Fig. 6 Spatial distribution of the daily values for the energy balance components in the reference semiarid area inside Petrolina County, Pernambuco, Brazilian Northeast. Latent heat flux $(\lambda E)$, sensible heat flux $(H)$, and ground heat flux $(G)$. Overbars mean average pixel values, shown together with the SDs. 
was higher than $R_{n}$, representing very well irrigated plots contrasting with the drier vicinity areas (see Figs. 5 and 6). The maximum $\lambda E$ values of $16 \mathrm{MJ} \mathrm{m}^{-2} \mathrm{~d}^{-1}$ return ET rates of $6.5 \mathrm{~mm} \mathrm{~d}^{-1}$, representing mostly irrigated orchards.

dos Santos et al., ${ }^{36}$ applying SEBAL and S-SEBI algorithms with Landsat images, reported maximum ET values of $6.0 \mathrm{~mm} \mathrm{~d}^{-1}$ in the mixed irrigated and natural agroecosystems under the semiarid Brazilian conditions. Also in a Brazilian semiarid region, but in this case using the METRIC model, Folhes et al. ${ }^{37}$ found low values for "Caatinga" $\left(<2.0 \mathrm{~mm} \mathrm{~d}^{-1} \sim<4.9 \mathrm{MJ} \mathrm{m}^{-2} \mathrm{~d}^{-1}\right.$ ), moderate values representing orchards (3.0 to $6.0 \mathrm{~mm} \mathrm{~d}^{-1} \sim$ 7.4 to $\left.14.7 \mathrm{MJ} \mathrm{m}^{-2} \mathrm{~d}^{-1}\right)$, and annual crops with the highest ET rates $\left(>6.0 \mathrm{~mm} \mathrm{~d}^{-1} \sim>\right.$ 14.7 $\mathrm{MJ} \mathrm{m}^{-2} \mathrm{~d}^{-1}$ ). The main reason for the slightly lower values of these last studies under irrigation conditions could be the image acquisition times, outside the rainy season, which are different from the current study in which the highest $\lambda E$ values were during the rainy period.

During the natural driest conditions of the year, between August and October, represented by the image of DOY 265, NV presented the lowest $\lambda E$ values, while irrigated fields showed the highest ones. Stomata of the natural species were close during this period, limiting transpiration and photosynthesis, while, in general, irrigation intervals in crops are short (daily irrigation), reducing the heat losses to the atmosphere.

The largest large-scale $\lambda E$ values for the mixed agroecosystems were in January (DOY 25) because of the joint effects of rains and irrigation together with high atmospheric demand (see Figs. 3 and 6). During this time of the year, the uniform soil moisture makes "Caatinga" have $\lambda E$ rates similar to those from ICs and even higher in some occasions. Intermediate $\lambda E$ values in NV ecosystem occurred after this period, in June (DOY 153), because the previous rainfalls still kept the natural species actively transpiring.

According to the $H$ spatial variations in Fig. 6, one can also distinguish irrigated areas from the "Caatinga" species by the lowest values in the first ecosystem, with some crop pixel values even being negative, meaning heat horizontal advection from the warmer $\mathrm{NV}$ at the vicinities of the irrigated plots, reaching up to $-7 \mathrm{MJ} \mathrm{m}^{-2} \mathrm{~d}^{-1}$. Although with smaller magnitudes, negative $H$ was also measured by eddy covariance system in irrigated orange orchards in the Mediterranean semiarid conditions of Sicily, Italy. ${ }^{38}$ The largest $H$ pixels corresponded to the lowest $\lambda E$ values in the image of DOY 265 (September), while the minimum $H$ ones were soon after the rainy period in June (DOY 153), due to low $R_{G}$ levels and high large-scale soil moisture.

The ground heat flux $(G)$ was the energy balance parameter that presented the lowest spatial variations among the Brazilian semiarid agroecosystems. Its values were very low, confirming that in most cases under semiarid conditions, they approach to zero at the daily scale, ${ }^{6,16,39}$ and could be neglected at this time-scale, as few areas presented daily values reaching up to around $1.0 \mathrm{MJ} \mathrm{m}^{-2} \mathrm{~d}^{-1}$.

Regarding the spatial variations, the lowest SD values for $\lambda E$ and $\mathrm{H}$ were soon after the rainy season. Under these conditions, the soil moisture in the root zone of all agroecosystems was high, but with all of them under low $R_{G}$ levels (see Figs. 3 and 6), situation represented by image of DOY 153 (June 2014).

Vegetation was classified into ICs and NV agroecosystems by applying the SUREAL algorithm [Eq. (17)] and the $r_{s}$ thresholds. ${ }^{24}$

Table 3 shows the daily average energy balance components together the evaporative fraction $\left[E_{f}=\lambda E /\left(R_{n}-G\right)\right]$ for ICs and NV, under different thermohydrological conditions in the reference semiarid region inside Petrolina County, Pernambuco, Northeast Brazil.

The lowest $R_{n}$ and $\lambda E$ average pixel values for the ICs agroecosystem were at the start of August (DOY 217), while the highest $R_{n}$ average was during the rainy period (DOY 25) and the one for $\lambda E$ occurred inside the climatically driest conditions represented by the image of DOY 265 (September). The $\lambda E$ and $R_{n}$ values produced a mean $E_{f}$ range from 0.66 to 0.81 , respectively, evidencing good soil moisture conditions in the root zone of the irrigated fruit crops. Consoli and Papa,${ }^{38}$ using field energy balance techniques with eddy covariance data, in irrigated orange orchards in the Mediterranean conditions, found a slightly lower average $\lambda E / R_{n}$ of 0.62 , when comparing with the current study. Bezerra et al. ${ }^{39}$ applying the Bowen ratio method in irrigated cotton crop in the Brazilian semiarid conditions, found values of $\lambda E / R_{n}$ ranging from 0.58 to 0.81 , similar to our results for ICs (from 0.63 to 0.79 , averaging 0.70 ). 
Table 3 Daily averages of the energy balance components for the mixed agroecosystems inside the reference semiarid area of Petrolina County, Pernambuco, Northeast Brazil: net radiation $\left(R_{n}\right)$, latent heat flux $(\lambda E)$, sensible heat flux $(H)$, soil heat flux $(G)$, and the evaporative fraction $\left\{E_{f}=\left[\lambda E /\left(R_{n}-G\right)\right]\right\}$.

\begin{tabular}{|c|c|c|c|c|c|c|c|c|c|c|}
\hline \multirow{2}{*}{$\frac{\text { DOY/mean }}{\text { DOY }}$} & \multicolumn{2}{|c|}{$R_{n}\left(\mathrm{MJ} \mathrm{m}^{-2} \mathrm{~d}^{-1}\right)$} & \multicolumn{2}{|c|}{$\lambda E\left(\mathrm{MJ} \mathrm{m}^{-2} \mathrm{~d}^{-1}\right)$} & \multicolumn{2}{|c|}{$H\left(\mathrm{MJ} \mathrm{m}^{-2} \mathrm{~d}^{-1}\right)$} & \multicolumn{2}{|c|}{$G\left(\mathrm{MJ} \mathrm{m}^{-2} \mathrm{~d}^{-1}\right)$} & \multicolumn{2}{|c|}{$E_{f}(-)$} \\
\hline & ICs & NV & ICs & NV & ICs & NV & ICs & $\mathrm{NV}$ & ICs & NV \\
\hline 25 & 11.33 & 11.29 & 7.77 & 4.25 & 3.21 & 6.77 & 0.39 & 0.39 & 0.71 & 0.39 \\
\hline 153 & 9.02 & 9.05 & 6.32 & 3.22 & 2.35 & 5.41 & 0.36 & 0.35 & 0.73 & 0.37 \\
\hline 217 & 8.97 & 9.08 & 5.69 & 1.75 & 2.91 & 6.80 & 0.35 & 0.33 & 0.66 & 0.20 \\
\hline 265 & 10.02 & 9.26 & 7.88 & 0.36 & 1.79 & 9.20 & 0.29 & 0.26 & 0.81 & 0.04 \\
\hline Mean & 9.84 & 9.67 & 6.92 & 2.40 & 2.57 & 7.05 & 0.35 & 0.33 & 0.73 & 0.25 \\
\hline
\end{tabular}

Note: ICs, irrigated crops; NV, natural vegetation; and DOY, day of the year.

Considering the NV ecosystem, the periods with the highest and the lowest mean $R_{n}$ values were the same of that for ICs, but for $\lambda E$ the smallest average happened in September (DOY 265 ), with the $E_{f}$ in this natural ecosystem ranging between 0.04 and 0.39 . The characteristics of the "Caatinga" natural species were manifested by low values of both $\lambda E$ and $E_{f}$, outside the rainy season. For ICs, the largest $E_{f}$ happened on occasions of heat advection from their surrounding natural drier areas.

Considering the whole year, $H$ mean pixel value for the NV ecosystem was almost three times larger than that for ICs. On average, $H$ reached 99\% of $R_{n}$ in September (DOY 265) for the first ecosystem, while the corresponding fraction for ICs was only $18 \%$ during this period. The average $H / R_{n}$ under the Mediterranean conditions ${ }^{38}$ of $30 \%$ was almost the same as the current study (26\%). The range of $H / R_{n}$ from 18 to $28 \%$ for the ICs agroecosystem is inside the values reported by Bezerra et al. ${ }^{39}$ for ICs under the semiarid conditions of the Northeast Brazil (11 to $29 \%)$.

Despite $G$ values of up to $1.0 \mathrm{MJ} \mathrm{m}^{-2} \mathrm{~d}^{-1}$ (see Fig. 6) in some areas, the 24-hour averages for both ICs and NV ecosystems were very low, with daily $G / R_{n}$ fractions ranging from only $3 \%$ to $4 \%$, with no perceptible spatial distinctions along the seasons among either agroecosystem. On one hand, Bezerra et al. ${ }^{39}$ reported $G / R_{n}$ daily values ranging as high as $15 \%$ in irrigated cotton crops under the Brazilian semiarid conditions. On the other hand, Consoli and Papa ${ }^{38}$ found lower 24-hour average $G / R_{n}$ of 0.01 in irrigated orange orchards in the Mediterranean semiarid climate. However, the daily fractions in the current study are in agreement with field measurements carried out by Teixeira et al. ${ }^{16}$ involving irrigated orchards and $\mathrm{NV}$ in the current study area. These $G / R_{n}$ differences could be due to different soil covers.

For the whole year of 2014, in average, the ratios $R_{n} / R_{G}, \lambda E / R_{n}, H / R_{n}$, and $G / R_{n}$ were $0.45,0.70,0.26$, and 0.04 , respectively, for the ICs ecosystem, while the corresponding ratios for the NV ecosystem were $0.45,0.25,0.72$, and 0.03 , respectively. The knowledge of these fractions is relevant to considering the land-use change effects, together with climate alterations and water scarcity.

The field eddy covariance and Bowen ratio measurements in ICs and NV in the study area previously done by Teixeira et al. ${ }^{16}$ returned respectively mean $E_{f}$ values of 0.80 and 0.30 , which are close to the average pixel values shown in Table 3 by applying the SAFER and SUREAL algorithms. The similarities of our large-scale results with field measurements in the study area and others from literature are encouraging, stimulating the use of these algorithms with the L8 satellite for quantifying the land-use effects on the energy exchanges in semiarid environments.

\section{Conclusions}

The joint use of L8 images and agrometeorological stations allowed the quantification and analyzes of the 24-hour radiation and energy balance components on large-scales in the year 2014, 
under different thermohydrological semiarid conditions in the Petrolina County, Pernambuco state, Northeast Brazil. $R_{n}$ was more strongly influenced by the solar radiation levels than by the characteristics of the different agroecosystems types, but the water and vegetation conditions were well identified from the energy partition patterns. It was demonstrated that the daily values of the latent $(\lambda E)$, sensible $(H)$, and ground $(G)$ heat fluxes can be estimated for ICs and $\mathrm{NV}$ from instantaneous measurements of the visible, near-infrared, and thermal radiations from the L8 sensor, through the application of the SAFER and SUREAL algorithms. The mean fractions of $\lambda E, H$, and $G$ to $R_{n}$ were $70 \%, 26 \%$, and $4 \%$, and $25 \%, 72 \%$, and $3 \%$, for ICs and NV agroecosystems, respectively. In some occasions, in well irrigated ICs, heat fluxes were evidenced coming from the NV dryer areas at their vicinities, promoting $\lambda E$ higher than $R_{n}$ and negative $H$ values. The large-scale analyses of the energy and mass exchange dynamics can contribute to the monitoring of the land-use and climate changes effects in the Brazilian semiarid region. The modeling success here gives more confidence for using the algorithms with L8 images together with weather stations in other semiarid environments around the world, which probably will need only calibrations of the original equations.

\section{References}

1. A. H. de C. Teixeira, "Determining regional actual evapotranspiration of irrigated and natural vegetation in the São Francisco river basin (Brazil) using remote sensing and Penman-Monteith equation," Rem. Sens. 2, 1287-1319 (2010).

2. D. G. Miralles et al., "Global land-surface evaporation estimated from satellite-based observations," Hydrol. Earth Syst. Sci. 15, 453-469 (2011).

3. M. C. Anderson et al., "Mapping daily evapotranspiration at Landsat spatial scales during BEAREX'08 field campaign," Adv. Water Res. 50, 162-177 (2012).

4. I. Pôças et al., "Using remote sensing energy balance and evapotranspiration to characterize Montane landscape vegetation with focus on grass and pasture lands," Int. J. Appl. Earth Obs. Geoinf. 21, 159-172 (2013).

5. R. G. Allen et al., Crop Evapotranspiration: Guidelines for Computing Crop Water Requirements, Food and Agriculture Organization of the United Nations, Rome, Italy (1998).

6. A. H. de C. Teixeira et al., "A comparative study of techniques for modeling the spatiotemporal distribution of heat and moisture fluxes in different agroecosystems in brazil," in Remote Sensing of Energy Fluxes and Soil Moisture Content, G. G. Petropoulos, Ed., 1st ed., pp. 169-191, CRC Group, Taylor and Francis, Boca Raton, Florida (2014).

7. W. G. M. Bastiaansssen et al., "A remote sensing surface energy balance algorithm for land (SEBAL) 1. Formulation," J. Hydrol. 212-213, 198-212 (1998).

8. G. J. Roerink, Z. Su, and M. Menenti, "S-SEBI: a simple remote sensing algorithm to estimate the surface energy balance," Phys. Chem. Earth 25, 147-157 (2000).

9. Z. Su, "The surface energy balance system (SEBS) for estimation of turbulent heat fluxes," Hydrol. Earth Syst. Sci. 6, 85-100 (2002).

10. A. H. de C. Teixeira et al., "Reviewing SEBAL input parameters for assessing evapotranspiration and water productivity for the low-middle São Francisco River basin, Brazil: part A: calibration and validation," Agric. For. Meteorol. 149, 462-476 (2009).

11. A. H. de C. Teixeira et al., "Reviewing SEBAL input parameters for assessing evapotranspiration and water productivity for the low-middle São Francisco River basin, Brazil: part B: application to the large scale," Agric. For. Meteorol. 149, 477-490 (2009).

12. H. A. Cleugh et al., "Regional evaporation estimates from flux tower and MODIS satellite data," Remote. Sens. Environ. 106, 285-304 (2007).

13. P. L. Nagler et al., "Estimating riparian and agricultural actual evapotranspiration by reference evapotranspiration and MODIS enhanced vegetation index," Remote Sens. 5, 3849-3871 (2013).

14. B. Kamble, A. Kilic, and K. Hubard, "Estimating crop coefficients using remote sensingbased vegetation index," Remote Sens. 5, 1588-1602 (2013).

15. R. G. Allen et al., "Satellite-based energy balance for mapping evapotranspiration with internalized calibration (METRIC)-Applications," J. Irrig. Drain. Eng. 133, 395-406 (2007). 
Teixeira et al.: Large-scale radiation and energy balances with Landsat 8 images and agrometeorological...

16. A. H. de C. Teixeira et al., "Analysis of energy fluxes and vegetation-atmosphere parameters in irrigated and natural ecosystems of semi-arid Brazil," J. Hydrol. 362, 110-127 (2008).

17. F. B. T. Hernandez et al., "Determining large scale actual evapotranspiration using agrometeorological and remote sensing data in the Northwest of Sao Paulo State, Brazil," Acta Hortic. 1038, 263-270 (2014).

18. Q. Vanhellemont and K. Ruddick, "Turbid wakes associated with offshore wind turbines observed with Landsat 8," Remote Sens. Environ. 145, 105-115 (2014).

19. A. H. de C. Teixeira et al., "Energy balance with Landsat images in irrigated central pivots with corn crop in the São Paulo State, Brazil," Proc. SPIE 9239, 923900 (2014).

20. A. H. de C. Teixeira, Water Productivity Assessments from Field to Large Scale: A Case Study in the Brazilian Semi-Arid Region, Lambert Academic Publishing, Saarbrücken, Germany (2009).

21. H. A. R. de Bruin and J. N. M. Stricker, "Evaporation of grass under non-restricted soil moisture conditions," Hydrol. Sci. 45, 391-406 (2000).

22. R. G. Allen, O. Hartogensis, and H. A. R. de Bruin, "Long-wave radiation over alfafa during the RAPID field campaign in southern Idaho," Research Report, University of Idaho, Kimberly (2000).

23. M. R. Raupasch, "Combination theory and equilibrium evaporation," Q. J. R. Meteorol. Soc. 127, 1149-1181 (2001).

24. A. H. de C. Teixeira, "Determination of surface resistance to evapotranspiration by remote sensing parameters in the semi-arid region of Brazil for land-use change analyses," C. M. U. Neale and M. H. Cosh, Eds., 1st ed., Vol. 352, pp. 167-170, IAHS Press, Wallingford, United Kingdom (2012).

25. S.-G. Li et al., "Energy partitioning and its biophysical controls above a grazing steppe in central Mongólia," Agric. For. Meteorol. 137, 89-106 (2006).

26. A. I. J. M. van Dijk, L. A. Bruijnzeel, and J. Schellekens, "Micrometeorology and water use of mixed crops in upland West Java, Indonesia," Agric. For. Meteorol. 124, 31-49 (2004).

27. J. L. Monteith and M. H. Unsworth, Principles of Environmental Physics, Arnold, London (1990).

28. J. S. Oguntoyinbo, "Reflection coefficient of natural vegetation, crops and urban surfaces in Nigeria," Q. J. R. Meteorol. Soc. 96, 430-441 (1970).

29. R. T. Pinker, O. E. Thompson, and T. F. Eck, "The albedo of a tropical evergreen forest," Q. J. R. Meteorol. Soc. 106, 551-558 (1980).

30. W. J. Shuttleworth, "Evaporation from Amazonian rain forest," Proc. R. Soc. London Biol. Sci. 233, 321-346 (1988).

31. D. B. Lobell and G. P. Asner, "Moisture effects on soil reflectance," Soil Sci. Soc. Am. J. 66, 722-727 (2002).

32. M. Yuan et al., "Assessment of crop growth and water productivity for five $\mathrm{C} 3$ species in the semi-arid Inner Mongolia," Agric. Water Manage. 122, 28-38 (2013).

33. M. Wang et al., "Vegetation primary production estimation at maize and alpine meadow over the Heihe River Basin, China," Int. J. Appl. Earth Obs. Geoinf. 17, 94-101 (2012).

34. I. A. M. Yunusa, R. R. Walker, and P. Lu, "Evapotranspiration components from energy balance, sapflow and microlysimetry techniques for an irrigated vineyard in inland Australia," Agric. For. Meteorol. 127, 93-107 (2004).

35. C. E. Hughes et al., "Estimating evapotranspiration for a temperate salt marsh Newcastle, Australia," Hydrol. Process 15, 957-975 (2001).

36. C. A. C. dos Santos et al., "Assessment of daily evapotranspiration with SEBAL and S-SEBI algorithms in cotton crop," Rev. Brasil. Meteorol. 25, 383-392 (2010).

37. M. T. Folhes, C. D. Rennó, and J. V. Soares, "Remote sensing for irrigation water management in the semi-arid Northeast of Brazil," Agric. Water Manage. 96, 1398-1408 (2009).

38. S. Consoli and R. Papa, "Corrected surface energy balance to measure and model the evapotranspiration of irrigated orange orchards in semi-arid Mediterranean conditions," Irrig. Sci. 31, 1159-1171 (2013).

39. B. G. Bezerra et al., "Surface energy exchange and evapotranspiration from cotton crop under full irrigation conditions in the Rio Grande do Norte State, Brazilian Semi-Arid," Bragantia 74, 120-128 (2015). 
Antônio Heriberto de Castro Teixeira is a researcher at Embrapa Satellite Monitoring. He received his BS degree in agronomy from Pernambuco Federal Rural University in 1988, his MS degree in meteorology from Paraíba Federal University in 1993, and his PhD in environmental sciences from Wageningen University in 2008. He is the author of more than 55 journal papers and has written one book and 23 book chapters. His current research interests include radiation and energy balances, evapotranspiration, biomass production, water productivity, and agrometeorological indices.

Janice Freitas Leivas is a researcher at Embrapa Satellite Monitoring. She received her BS degree in meteorology at the Federal University of Pelotas (UFPEL) in 2003 and her MS degree in agricultural climatology statistics at Federal University of Rio Grande do Sul (UFRGS) in 2003, and her $\mathrm{PhD}$ in agrometeorology, at UFRGS in 2008. Her actual research activities are concentrated on remote sensing applications.

Fernando Braz Tangerino Hernandez graduated in agronomic engineering in 1987 and received his MS degree in agronomy (vegetal production) at the São Paulo State UniversityUNESP in 1987 and PhD in irrigation and drainage from Superior Luiz de Queiroz-USP in 1995. Currently, he is a senior professor at UNESP. He has experience on agricultural engineer, with emphasis on irrigation and drainage, mainly in the following research fields: irrigated agriculture, agrometeorology, and hydrology.

Renato Alberto Momesso Franco is a biologist and has BS, MS and PhD degrees from the São Paulo State University. He has been working as a researcher with emphasis on water resources, remote sensing and geographic information systems. 